\title{
RECENT THERMOPHYSICAL DEVELOPMENTS ON NUCLEAR MATERIALS*
}

\author{
Edgar F. WESTRUM, Jr. \\ Department of Chemistry, University of Michigan, Ann. Arbor, Michigan, USA
}

\begin{abstract}
The current status of chemical thermodynamics of the actinide and lanthanide chalcogenides including high-temperature adiabatic calorimetry of these important compounds (with stress on their electronic, magnetic, order-disorder, disproportionation transitions), as well as the spin-wave magnetic contributions, is reviewed. Schottky anomalies (and the information they yield on crystal-field level splitting), definitive resolution of lattice and magnetic contributions for both first- and second-order phase transitions, and other unusual aspects of phase behavior are considered. Unpublished work on the uranium trioxides, the non-stoichiometric and metastable tetrauranium octaoxides, the uranates, etc. is included. The close parallel between actinide and lanthanide behavior evidenced by our recent unpublished thermal studies on the actinide and lanthanide trichlorides, and hexaborides is emphasized.
\end{abstract}

On passe en revue l'état actuel de la thermodynamique chimique des chalcogeniures d'actinides et de lanthanides en incluant la calorimétrie adiabatique à haute température de ces importants composés et en insistant sur leurs transitions électronique, magnétique, ordre-désordre aussi bien que sur les contributions magnétiques onde-spin. Les anomalies de Schottky (et l'information qu'elles fournissent sur l'écart de niveau champ-cristal), la résolution définitive des contributions réticulaire et magnétique à la fois pour les transformations de phase de premier et de second ordre et d'autres aspects inhabituels du comportement des phases sont considérés. Les recherches non publiées sur les trioxydes d'uranium, les octaoxydes d'uranium tétravalent non-stoechiométrique et métastable sont incluses. On met l'accent sur le parallélisme étroit entre le comportement des actinides et des lanthanides mis en évidence par nos études thermiques récentes non publiées sur les trichlorures d'actinide et de lanthanide et des hexaborures.

Es wird ein U̇berblick über den gegenwärtigen Stand der chemischen Thermodynamik der Chalkogenide der Actinoiden und Lanthanoiden einschliesslich der adiabatischen Hochtemperaturkalorimetrie mit Hinblick auf deren elektronische, magnetische, Ordnungs-Unordnungs- und Disproportionierungs-übergänge sowie magnetische Spinanteile gegeben. Es werden die SchottkyAnomalien und die Informationen, aus denen sich die Kristallfeldaufspaltung ergibt, ferner die Aufspaltung der Gitter- und magnetischen Anteile an Phasenumwandlungen erster und zweiter Ordnung und andere ungewöhnliche Aspekte des Phasenverhaltens in Betracht gezogen. Unveröffentlichte Ergebnisse an Urantrioxiden, unstöchiometrischen und metastabilen Tetrauranoctoxiden, Uranaten, usw. ergänzen die Arbeit. Auf das sehr ähnliche Verhalten zwischen den Actinoiden und Lanthanoiden aufgrund neuerer unveröffentlichter thermischer Untersuchungen an Trichloriden und Hexaboriden der Actinoiden und Lanthanoiden wird hingewiesen.

\section{Introduction}

Although substantial progress has been made in approximately the last decade on the investigation of the chemical properties of the metals and compounds of the actinides, of the lanthanides, and of the transition element fission products and some very interesting measurements have been reported, the total scope

*Supported by U.S. Atomic Energy Commission and the National Science Foundation. implied by the title "Nuclear Materials" is too broad to encompass in a brief presentation. Consequently, I have chosen to discuss primarily thermophysical measurements on these substances with decreasing emphasis in the order stated.

Much of the related work on other materials of nuclear import will remain uncovered for lack of time and even within the area of major emphasis some choice had to be made in the presentation of the most interesting work on these groups of materials.

Unquestionably, many important contributions 
have been slighted, and emphasis has been placed on the areas of greatest familiarity to the author. In many instances, lacunae are pointed out but one cannot escape the feeling that we are still overlooking a fertile field of potential investigation spiced with many intriguing prospects for future endeavor. On the other hand, practical thermodynamicists cannot be other than concerned with the fact that in this country at least many of the most productive centers of cryogenic and higher temperature thermophysical research (particularly those that have a tradition of involvement with nuclear materials) have been curtailed, eliminated, or otherwise handicapped by the present decline of scientific financing. Perhaps we must look over the next few years with increasing interest at the high productivity which has become increasingly characteristic of calorimetric and thermodynamic scientists in Japan, in the Soviet Union, and perhaps soon on the Chinese mainland. In any event, I would like to express my appreciation for the opportunity of the interchange which is provided by the present Seminar. Before becoming too involved in the aspects of the scientific problem, I should like to suggest that it would be advantageous for thermodynamicists and phase behavior scientists involved with the several national atomic commissions, with the International Atomic Energy Agency or within international scientific unions to concern themselves with the scientific and technological applications of thermodynamic and phase behavior data on nuclear materials. In particular, careful thought should be taken to achieve the following goals:

(1) To extend and improve technological and other practical applications of thermodynamic principles and data;

(2) To avoid excessive duplication of endeavor and to outline areas where experimental research on thermodynamic properties might well be intensified advantageously;

(3) To extend and to streamline the compilation of thermodynamic properties of important materials in the nuclear energy program; and

(4) To make a concerted effort in the development of a greater understanding of phase stability in relation to bond structure for the prime purpose of improving methods for the estimation of thermodynamic data.

Such an endeavor would serve the multiple pur- poses of making potential users more aware of the importance of thermodynamics in solving technological problems in the nuclcar area, emphasize problems in the compilation and accessibility of such data, and perhaps accelerate the production of the more urgently needed items by providing potential sponsors with a documented argument for the urgency of attention to these areas. An initiatory endeavor to distribute such a discussion-report has already been achieved for high-temperature metallurgical systems [1].

Within the United States, the national efforts in data evaluation, both in the public and the private domain, seem not to be expanding; economic limitations and pressures to recover operational costs are affecting the level of operations unfavorably. However, the National Data Advisory Board attempts to create more awareness for data evaluation needs for research and development, to increase the involvement of private industry, and - through the United States National Committee for CODATA - to promote integration of national and international endeavors in all the physical sciences.

\section{Significantly improved calorimetric techniques}

Although calorimetric techniques generally improve gradually rather than discontinuously, several developments in recent years are of sufficient significance to merit special attention.

One of the first of these is the laser calorimetry developed by Professor Takahashi and his colleagues. This is a tremendously exciting technique and one of which I shall not say more since he is here and will speak on the subject himself.

\subsection{High-frequency relaxation method}

A second method of heat-capacity measurement which bears consideration is that of the high-frequency relaxation (HFR) method for measuring the magnetic specific heat, $C$. The basic method, originally devised by Casimir and du Pré, uses purely magnetic measurements to determine $C$ without the usual uncertainty due to the resolution of the generally much larger lattice specific heat, and it thus allows accurate estimates over wide ranges of temperature. The recent 
development of cryogenic tunnel diode oscillators has been used to improve and extend this method by Skjeltorp and Wolf [2]. At temperatures high compared with the onset of magnetic ordering, $C$ can be fitted to a series expansion of the form

$$
C / R=C_{2} / T^{2}+C_{3} / T^{3}+\ldots,
$$

where the parameters depend on the number of magnetic spins and in suitable cases can be related to microscopic spin-spin interaction constants. Additional information can also be obtained from the field dependence of $C$, which can be related to the temperature dependence of the isothermal susceptibility. Examples of materials for which this technique has been used successfully include rare earth halides, hydroxides and garnets, but many other lanthanide and actinide materials should satisfy the conditions under which this method can be applied. It has already been applied to the study of the magnetic and thermal properties of $\mathrm{Gd}(\mathrm{OH})_{3}, \mathrm{~Tb}(\mathrm{OH})_{3}$ and $\mathrm{GdCl}_{3}$ [3-5].

\subsection{Low-temperature laser calorimetry}

$\mathrm{A}^{3} \mathrm{He}$ calorimeter with rapid responses, useful for the measurement of small heat capacities below $1 \mathrm{~K}$ has also been reported by Golbrecht et al. [6]. This calorimeter employed a superconducting heat switch, achieved thermal equilibrium within 1 to $2 \mathrm{~s}$ with metallic samples and permitted a measurement of heat capacities as small as $30 \mu \mathrm{J} / \mathrm{K}$ with a precision of $1 \%$ above $0.4 \mathrm{~K}$ at a rate of 80 heat capacity points per hour.

Heat capacities one or two orders of magnitude smaller than those typically measured in this range were involved during study on the antiferromagnetic ordering of praseodymium hexaboride in the range 2 to $20 \mathrm{~K}$. Lee et al. [7] initially used the pulse technique of Morin and Maita [8]. Lee found that the heat pulse method in the vicinity of the Néel point (near $7 \mathrm{~K}$ ) where the heat capacity was large, required correspondingly long times to establish thermal equilibrium after application of heat pulse. In order to ascertain the possible presence of an isothermal absorption of heat on a small $(30 \mathrm{mg})$ sample, a dynamical temperature relaxation method employing heating by laser beams was developed by Lee et al. [7]. This involves the use of laser radiation to heat the sample - a technique which had been pioneered at higher temperatures [9] in Japan.

In the experimental arrangement employed, a silicon bolometer with a thin diffusion-doped layer on one side was employed as temperature sensor. At low temperatures the entire wafer except the diffused layer is insulating. The layer resistance was used as a means of indicating temperature of the sample (which was bonded to the insulating side by ultrasonic soldering). Electrical contact and mechanical support for the bolometer were established by means of fine gold wires thermally anchored to a copper block the temperature of which could be varied with a heater and sensed with a thermocouple. Both sample and bolometer were heated by a laser beam directed down a light pipe into the evacuated cryostat which was immersed in liquid helium.

In Lee's method the laser beam is switched on suddenly and the time constant of the resulting thermal relaxation is used to deduce the heat capacity. By operating a bolometer in a constant current mode, Lee was able to describe the small exponentiallysaturating temperature produced by the incident radiation in terms of a time constant. A determination of the time constant then provides an absolute measurement of heat capacity provided thermal equilibrium between bolometer and sample is established in a time short compared to $\tau$.

To verify that this was indeed the case a variant of the ac temperature technique of Sullivan and Seidel [10] in which the laser radiation is chopped at fixed frequencies and the ac component of the bolometer voltage is detected with a lock-in amplifier was used. The frequency dependence of the ac signal provides a measure of the internal time constant.

\subsection{High-pressure calorimetry}

One of the least popular variables among calorimetrists of all temperature persuasions seems to be pressure. However, a simple high-pressure calorimeter has been devised by Smith and Phillips [11]. This calorimeter consists of a small piston and cylinder arrangement with a mass of about $150 \mathrm{~g}$ constructed entirely fiom high-purity $\mathrm{Cu}-\mathrm{Be}$ alloy $(2.1 \mathrm{wt} \% \mathrm{Be})$ which was heat-treated to full hardness. The sample is placed in a close-fitting Teflon sleeve between two 
Teflon discs. The cell is supported by an external screw-on collar and pressures applied to the sample at room temperature in a standard press. At the required pressure, the locking screw is tightened down onto the internal piston and the calorimeter is removed from the press and is installed in a ${ }^{3} \mathrm{He}$ cryostat. Since the heat capacity of the sample comprises typically only 3 to $5 \%$ of the total measured heat capacity, reasonably high precision is needed in the measurement of heat capacities of the cell both filled and empty. This device has been used for studies of the superconductivity of $\alpha$-uranium to pressures as high as $10 \mathrm{kbar}$ and on the electronic properties of a $\alpha$-Ce at pressures as high as $11 \mathrm{kbar}$.

\subsection{Computerization}

Science, like haute couture, has its fashions. Automation these days enables you to load your calorimeter, press the button, go to lunch or to Monte Carlo - depending on the duration of the experiment and one's financial status. When you do come back to the desk you may pick up the computer output with all the relevant data transposed into a format suitable for printing the tables of data and possibly of derived thermodynamic functions. In most instances, some degree of semi-automatic and semi-manual operation seems to be the preferred solution but in some instances an on-line computer may actually be used to operate the calorimeter.

The treatment of heat capacity data by digital computers is rapidly becoming the rule rather than the exception and is typified by the methods employed by Osborne et al. [12] .

\section{Lanthanide compounds}

Although actinide compounds have an obvious nuclear technological import, data on the corresponding lanthanide compounds provide a very useful extension of parameters as well as a basis for understanding the more complex relationships existing over truncated ranges in the actinides. For example, the five $5 f-6 d$ electronic orbital problem makes interpretation of the thermophysical, electronic, and magnetic data especially difficult. The complications introduced in both series by the conduction electrons hinders facile interpretation. The thermal properties of the lanthanide hexaborides, for example, are shown to exhibit largely unexplained anomalies and like many of the other lanthanide compounds discussed, offer interesting possibilities for technological and possibly nuclear applications. The availability of a fairly recent summary of the thermodynamic and magnetic properties of the lanthanide chalcogenides, the pnictides and binary semi-metallic compounds [13] as well as an excellent critical assessment of the enthalpies, entropies, and Gibbs energies of formation of the lanthanide oxides compiled by Holley et al. [14] largely eliminates need for further comments. Unfortunately, to the best knowledge of the author, this interesting series of reviews under the editorship of Professor Eyring has not been continued in recent years..

\subsection{Lanthanide sesquioxides}

Although resolution of the levels resulting from splitting of the ionic ground state by the crystal fields is usually achieved by spectroscopists, on occasion the cryogenic calorimeter can do yeoman service, especially in the absence of optical grade samples.

Subsequent to earlier heat capacity measurements on $\mathrm{La}$ (III) and on $\mathrm{Nd}$ (III) oxides and deduced crystal field splitting of the ground electronic level of the former sesquioxide, the spectrum of $\mathrm{Nd}(\mathrm{III})$ ion in a La(III) oxide host was observed by Henderson et al. [15]. They report five crystal field lines for the ground state $\left({ }^{4} I_{9 / 2}\right)$ at $0,23,84,253$, and $496 \mathrm{~cm}^{-1}$. The first two excited levels are in excellent accord with corresponding values deduced from heat capacity data alone $\left(0,21,81\right.$ and $\left.400 \mathrm{~cm}^{-1}\right)$, and the center of density of the higher levels also corresponds. However, the interpretation of the electronic heat capacity data of the cubic Gd(III), Dy(III), Ho(III), and Er(III) oxides was hampered by the lack of spectral data. These cubic lattices have two non-equivalent types of cation sites. Threefourths of the cations have $\mathrm{C}_{2}$ symmetry. The remaining cations possess $\mathrm{C}_{3 \mathrm{i}}$ symmetry. The spectra reported for Dy(III) [16], Er(III) $[17,18]$, and $\mathrm{Tm}(\mathrm{III})$ ions [18] with $\mathrm{C}_{2}$ symmetry in $\mathrm{Yt}(\mathrm{III})$ oxide or in single crystal Ln(III) oxides together with heat capacity data permitted derivation of the lattice heat capacity for the cubic oxides from $\mathrm{Gd}_{2} \mathrm{O}_{3}$ to $\mathrm{Lu}_{2} \mathrm{O}_{3}$ 

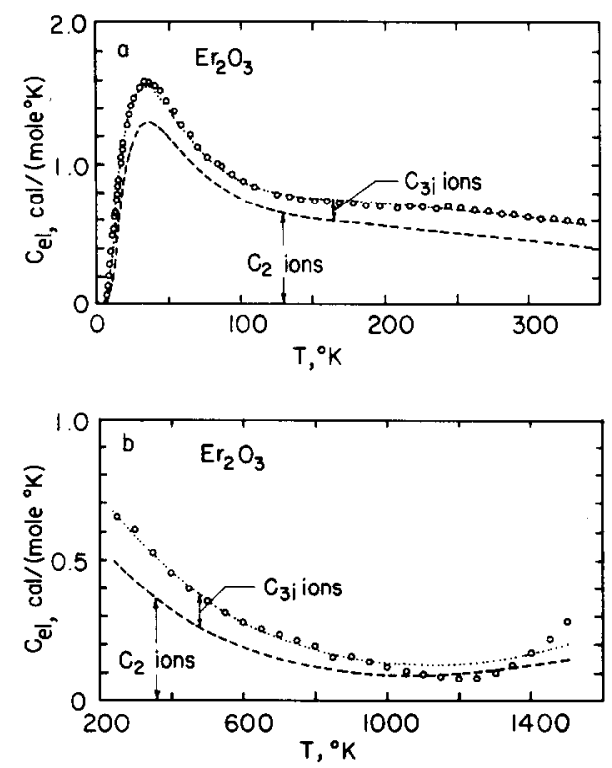

Fig. 1. Schottky (excess) heat capacity of $\mathrm{Er}_{2} \mathrm{O}_{3}$ [19]. In fig. 1a the circles represent data from this laboratory. The dashed curves represent the calculated electronic heat capacity of the $\mathrm{C}_{2}$ ions based on the spectroscopic data of Kisliuk et al. [17], and Gruber et al. [18]; the dotted curve shows total electronic heat capacity by adding the contribution for the $\mathrm{C}_{3 \mathfrak{1}}$ levels. In fig. $1 \mathrm{~b}$ the circles represent heat capacities from enthalpy increment determinations of Pankratz and King, and the curves have the same significance.

and energy levels for the $\mathrm{C}_{3 \mathrm{i}}$ ions in $\mathrm{Dy}_{2} \mathrm{O}_{3}, \mathrm{Er}_{2} \mathrm{O}_{3}$ and $\mathrm{Tm}_{2} \mathrm{O}_{3}$ [19]. As an example of the success of the method consider $\mathrm{Er}_{2} \mathrm{O}_{3}$ [19] as represented in fig. 1 . Contributions to the electronic heat capacity, $C_{\mathrm{el}}$, based on spectroscopic levels reported for the $\mathrm{C}_{2}$-type ions in $\operatorname{Er}(\mathrm{III})$ oxide $[17,18]$ consisting of doublets at $0,39,76,89,158,258,495$, and $500 \mathrm{~cm}^{-1}$, are represented by dashed curves in fig. 1 which depicts $C_{\mathrm{el}}$ for the low-temperature region. These values were derived by subtracting the lattice contribution from the apparent heat capacities. The $C_{\mathrm{el}}$ remaining after removal of the contributions of the $\mathrm{C}_{2}$ ions is attributed to the levels in the $\mathrm{C}_{3 \mathrm{i}}$ ions. The levels and their degeneracies are deduced in part from the position and magnitude of the Schottky peaks in the observed $C_{\mathrm{e} 1}$ (for separations of less than $100 \mathrm{~cm}^{-1}$ ) and in part from the splittings of the ground state term by fourth-and sixth-order terms of cubic crystal fields. The levels thus derived are doublets at $0,12,50,55,150$, and $450 \mathrm{~cm}^{-1}$ and a quar- tet at $550 \mathrm{~cm}^{-1}$. These correspond most closely to the levels in a cubic field with a ratio of sixth- to fourth-order terms $\left(V_{6} / V_{4}\right)$ of 0.25 . The $\Gamma_{8}$ level is split to 12 and 50 (or 55 ) $\mathrm{cm}^{-1}$, and the second $\Gamma_{8}$ level is split to 150 and $450 \mathrm{~cm}^{-1}$. The $C_{\mathrm{e} 1}$ data require levels at 12,50 , and $55 \mathrm{~cm}^{-1}( \pm 10 \%$ of $\Delta E)$.

On the high-temperature aspects, the enthalpy determinations of Tsagareisheili are of considerable interest. Many of these extend up to $1600 \mathrm{~K}$ and they include the sesquioxides of lanthanum, lutetium [20], yttrium and cerium (dioxide) [21], scandium [22], gadolinium [23], samarium and europium [24], and erbium [25].

Enthalpies of formation of lanthanide sesquioxides have also been determined recently at the Los Alamos Scientific Laboratory under the direction of Drs. C.E. Holley, Jr. and E.J. Huber. Because Dr. Holley is at this meeting, he will present this work himself, and since much of it has already been reviewed [14], I will make no further comments on it except to say that the data have been of great utility in ascertaining the relative stabilities of the $\mathrm{B}$ and $\mathrm{C}$ forms of some of the sesquioxides [26].

\subsection{Lanthanide chalcogenides}

Cryogenic heat capacities have been reported for $\mathrm{NdS}, \mathrm{LaSe}, \mathrm{LaTe}$ and for lanthanide sesquichalcogenides [27-31] and for lanthanide chalcogenides of the formula $\mathrm{Ln}_{3} \mathrm{Ch}_{4}$ [32]. High-temperature enthalpies of the europium chalcogenides have been determined to $1725 \mathrm{~K} \mathrm{[33].}$

\subsection{Lanthanide halides}

Thomas Deline has completed measurements between 5 and $350 \mathrm{~K}$ on europium tribromide in collaboration with Professor John Haschke and the present author [34]. No anomalous behavior was observed over the temperature region in question although there is every expectation that transitions will occur at lower temperatures. James Sommers is undertaking a study of an extensive series of the lighter lanthanide trichlorides over the same range of temperature. Preparation of the compounds is well underway, but no actual measurements have as yet been made. Except for measurements made in the vicinity of $1-2 \mathrm{~K}$ by Colwell [35] together with 
high-temperature enthalpy-type measurements by Bredig [36] and his colleagues, little thermophysical work has been done on the lanthanide halides. It is true that some heat capacity measurements have been on hydrated materials [37] and these have been analyzed by Cobble for estimates of the thermodynamic properties [38].

Recent magnetic studies have revealed canted antiferromagnetic ordering of the gadolinium trichloride moments below $2 \mathrm{~K} \mathrm{[39]} \mathrm{as} \mathrm{well} \mathrm{as} \mathrm{some}$ correlation (and lack thereof) between the magnetic and thermal properties of the trihalides [40]. Thermal studies of entropies and crystal field splittings have been reported for four of the trichloride hexahydrates [37]. Higher temperature studies include vaporization behavior, phase equilibria and thermodynamic properties [41], enthalpy of fusion of $\mathrm{SmF}_{3}$ [42], enthalpies of seven trifluorides [43], of the vapor formation of several trichlorides [44] and oxychlorides [45] as well as high-temperature thermodynamic properties of fluorides [46] and enthalpies of formation of fluorides [47].

\subsection{Lanthanide hexaborides}

These electrically conducting substances pose significant problems in the interpretation of their thermal anomalies and consequently of their thermodynamics. The heat capacity of $\mathrm{LaB}_{6}$ is of normal sigmate behavior without thermal anomalies; the other hexaborides studied all show cooperative, antito paramagnetic $\lambda$-type transitions near $10 \mathrm{~K}$ followed by complex Schuttky transitions with maxima between 20 and $80 \mathrm{~K}$ [48]. The resolution of the magnetic and electronic contributions for the $\mathrm{LnB}_{6}$ 's was achieved by means of the heat capacity of diamagnetic $L_{a} B_{6}$ as an estimate of the lattice vibrational heat capacity. For $\mathrm{NdB}_{6}$, the Schottky anomalies were resolved in terms of energy levels $(2,4,4$ at 230 and $640 \mathrm{cal} / \mathrm{mole} \mathrm{K}$ ) [49] generated by the crys. tal field splitting of the ten-fold degenerate ground state of the assumed Nd(III) ions [4]. The data on $\mathrm{PrB}_{6}$ and $\mathrm{CeB}_{6}(\lambda$-transition at $7 \mathrm{~K}$, Schottky at $35 \mathrm{~K}$ ) appear to be interpretable on a basis similar to that for $\mathrm{NdB}_{6}$ [48].

However, the results for $\mathrm{GdB}_{6}(\lambda$-anomaly at $16 \mathrm{~K}$, Schottky maximum at $30 \mathrm{~K}$ corresponding to a splitting of $61.3 \mathrm{~cm}^{-1}$ ) are inconsistent with the much smaller expected crystal field splitting of an ${ }^{8} S_{7 / 2}$ ground state. No cogent explanation of the anomaly has yet been postulated. The total transitional entropy in $\mathrm{GdB}_{6}$ and other properties (lattice parameters, Mössbauer and adsorption spectra, mag. netic susceptibility, etc.) cast considerable doubt that lanthanide metals are in fact in III oxidation states in some of the hexaborides. Since $\mathrm{EuB}_{6}, \mathrm{Yb}_{6}, \mathrm{SmB}_{6}$, and the alkaline earth hexaborides all contain divalent metal ions, this state may obtain at low temperatures in other lanthanide hexaborides [50].

Further interesting work on these materials includes the unpublished data of Westrum et al. [34], the low-temperature heat capacities determined at Talence [51] as well as the less quantitative work reported by Geballe et al. [52] and by Matthias [53].

\subsection{Lanthanide pnictides}

Among the most interesting studies reported on these substances are the low-temperature heat capacities which exhibit Schottky-type thermal anomalies in some of the lanthanide bismuthides and antimonides; these anomalies are among the crystal field effects reported by Wallace [54]. From low-temperature studies on the electrical and magnetic properties of lanthanide nitrides [55] and the heat capacity from 1.7 to $270 \mathrm{~K}$ [56], the spontaneous magnetiza* tion and the magnetic heat capacity below the ordering temperatures have been evaluated as well as the splitting of the ground-state multiplet. Thermodynamic functions have been evaluated [34] from these data.

\subsection{Miscellaneous}

Developments in the chemical thermodynamics of the lanthanides have been discussed [57] and the estimation and the evaluation of the entropies for related compounds provided. Optical spectral studies of low 4 f levels of the lanthanides have been summarized by (the late) G.H. Dieke [58] .

The status of thermal and thermochemical data has been evaluated for the semi-metallic compounds of both lanthanides and actinides [59]. 


\section{Thermodynamics of the actinides}

\subsection{Metals}

Data on the heat capacity of uranium [60-62], on neptunium [63], and on plutonium-242 [64-66] have been reviewed by Mendelssohn [67] and the values for thorium and protactinium included.

\subsection{Oxides}

The definitive paper on low-temperature heat capacity of uranium dioxide establishes the $\lambda$-type anomaly at $30.44 \mathrm{~K}[68]$. The data are compared with neutron scattering results. A number of recent studies extend high-temperature enthalpies to the melting point [69-72]. Two high-precision studies by different techniques $[73,74]$ are remarkable in their close accord although done independently by different techniques. Enthalpy data on the gaseous phase have been fit to a theoretically derived equation [75].

Among the several studies dealing with the interesting thermodynamic properties of $\mathrm{U}_{4} \mathrm{O}_{9}$ are the three indicated here [76-78]. High-temperature transformations in lanthanide oxides and related thermophysical information have been summarized

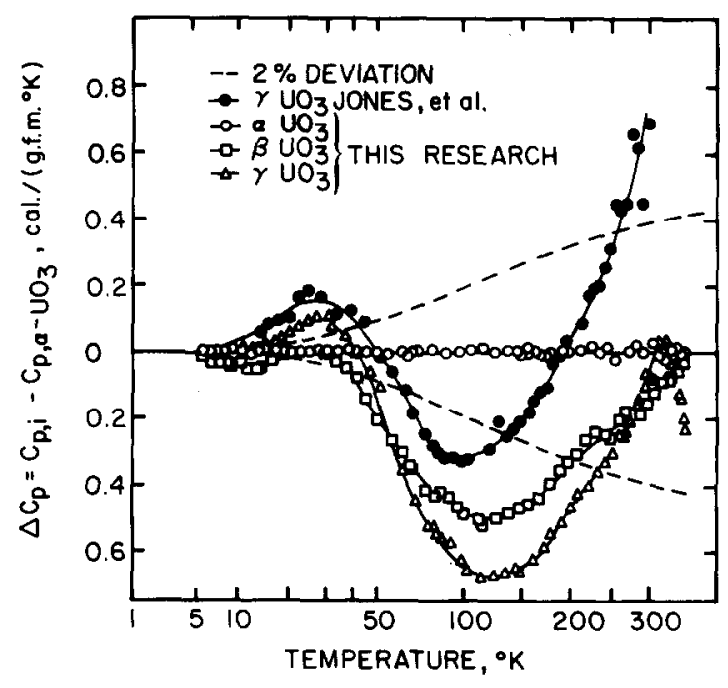

Fig. 2. Low temperature relative heat capacities of $\mathrm{UO}_{3}$ [86]. and reviewed by others [79-81]. High-temperature thermodynamic properties of some uranium oxides have been ascertained from EMF cell measurements in Rumania [82]. The same laboratory has reported high-temperature enthalpy and related thermodynamic functions on stoichiometric and non-stoichiometric uranium oxides [83] but it is difficult to correlate these results with other data reported in the literature.

Iligh-temperature enthalpy data to $1000 \mathrm{~K}$ on $\mathrm{U}_{3} \mathrm{O}_{8}$ [84] to supplement the earlier cryogenic values [85] have been obtained. The $\alpha-, \beta$-, and $\gamma-\mathrm{UO}_{3}$ phases have been investigated over both highand cryogenic-temperature ranges by Cordefunke and Westrum [86]. The results are especially interesting at low temperatures as shown in fig. 2.

The thermodynamics of hypostoichiometric uranium dioxides have been investigated from the study of oxygen partial pressures in two laboratories $[87,88]$. At the same time a new technique of gas equilibration in a sealed silica system has been developed to obtain thermodynamic data for both the hypo- and hyperstoichiometric dioxide [89]. A definitive study by Gr $\phi$ nvold et al. [90] permits an interesting resolution of the electronic energy levels and other contributions. Marchidan [91] also studied non-stoichiometric oxides at high temperatures. A most exciting pioneer study involving the direct determination of specific enthalpies of oxygen in $\mathrm{UO}_{2+x}$ by Gerdanian and Dodé has been reported [92].

The gas phase properties of uranium dioxide have been evaluated from spectral data [93] .

For $\mathrm{PuO}_{2}$, the low-temperature data of Sandenaw and of Kruger have been supplemented by enthalpy data between 192 and $1400 \mathrm{~K}$ [94] and from 1500 to $2715 \mathrm{~K}$ [95] and interpreted by Manes [96]. Unfortunately the stored energy matter is problematical in ${ }^{239} \mathrm{Pu}$; recent results from the Argonne Nationa) Laboratory indicate that the long awaited availability of ${ }^{244} \mathrm{Pu}$ will provide better, more reliable dataespecially in the cryogenic region.

Data on $\mathrm{PuO}_{2}-\mathrm{UO}_{2}$ solid solutions are also available [97-99].

\subsection{Other uranium chalcogenides}

Here data are sparser. Cryogenic data on ThS 
[100], US [101], and USe [102], are representative. Enthalpy data extend to $1800 \mathrm{~K}$ [103]. Other chalcogenides recently studied are $\mathrm{US}_{2}$ and $\mathrm{US}_{3}[104]$ as well as $\mathrm{US}_{1.9}$ and $\mathrm{USe}_{2}$ [105]. Heat capacities of solid solutions of US-UP have been studied over the cryogenic region [106].

\subsection{Carbides}

Cryogenic heat capacity data on UC $[107,108]$, $\mathrm{UC}_{1.91}[108], \mathrm{ThC}_{2 \pm x}[109]$, and $\mathrm{U}_{2} \mathrm{C}_{3}$ [108] are supplemented by enthalpy data to $925 \mathrm{~K}[110,111]$. $\mathrm{NpC}_{0.91}$ [112], $\mathrm{PuC}_{0.81}$ [113], and $\mathrm{Pu}_{2} \mathrm{C}_{3}$ [114] have been studied also.

\subsection{Pnictides}

Low-temperature $C_{\mathrm{p}}$ on UN [115-117], higher temperature enthalpy data $[107,118-120]$, and thermochemical and phase equilibrium data have been reviewed $[121,122]$. Tagawa has considered the equilibrium nitrogen pressure data for $\mathrm{U}_{2} \mathrm{~N}_{3}$ [123] . Cryogenic heat capacities exist for $\mathrm{UN}_{1.91}, \mathrm{Un}_{1.59}$, and $U N_{1.73}[108]$

\subsection{Borides}

Uranium diboride's heat capacity has been studied from 1 to $350 \mathrm{~K}$ [124], from 600 to $1500 \mathrm{~K}$ [125], and from 1300 to $2300 \mathrm{~K}$ [126].

\subsection{Halides}

Little recent work exists, but enthalpies of fusion for $\mathrm{UF}_{4}$ [127] are revealing in comparison with that of $\mathrm{ZrF}_{4}$.

\subsection{Miscellaneous}

The chemical thermodynamic properties of plutonium have been compiled by Oetting [128] and by Rand et al. [129].

\section{Thermodynamics of fission products}

\subsection{Molybdenum compounds}

Over the past several years Mr. Harmas Kiwia (of
Tanzania) has been undertaking an intensive investigation of the thermodynamics of important molybdenum compounds on which thermophysical data are virtually totally lacking. This endeavor [34] is timely in the sense that the Soviet compilers have just completed an analysis of the recently available thermochemical Russian data on the enthalpies of formation of many of these materials. At the present time, studies on the $\mathrm{MoSe}_{2}$ and $\mathrm{MoTe}_{2}$ have been completed. These supplement the (still) unpublished data [130] on $\mathrm{MoS}_{2}$. These data are of considerable interest from another point of view since the limiting law behavior of the heat capacity of essentially the lamellar lattices has been claimed to follow a $T^{2}$ depen. dence. I think that we have largely laid this ghost to rest and established by our earlier work in boron nitride and other substances that a $T^{3}$ behavior obtains and that the interaction between parallel layers is by no means totally negligible. However, the data on these three molybdenum chalcogenides which form a sandwich-layer-lattice should remove any remaining doubt. In addition to these three compounds, we have studied enthalpies at low temperatures on $\mathrm{MoO}_{2} \mathrm{Cl}_{2}, \mathrm{MoOCl}_{3}$ and $\mathrm{MoOCl}_{4}$ and should very soon be in a position to define the relative stabilities of these materials. In addition, heat capacities have been measured on $\mathrm{MoCl}_{3}$ and $\mathrm{MoCl}_{4}$ while those on $\mathrm{MoCl}_{5}$ are in progress. Although gaps still exist in thermophysical properties of molybdenum compounds it is believed that this increment of nine compounds combined with the thermochemical data recently obtained in the USSR will do much to set this region of the periodic table in order from the point of view of thermodynamic stability.

\subsection{Molten salts}

Although this area is one of acknowledged relevance and spice insofar as actinide thermodynamics are concerned, it has not been incorporated within the scope of this review. It can be expected, however, to be an area of enhanced importance over the next decade insofar as nuclear thermodynamics are concerned.

\section{Acknowledgements}

The research endeavors of the author and his re- 
search group have been funded for several decades by the Atomic Energy Commission. At the present time such studies as are undertaken in this area are funded largely by the National Science Foundation. Appreciation is expressed to both sponsors for the enabling financial support which made these studies possible.

\section{References}

[1] P. Grieveson and K.C. Mills, Metals and Materials, Part I, 46 (November 1972); Part II, 46 (December 1972); Part III, 88 (February 1973).

[2] A.T. Skjeltrop and W.P. Wolf, Phys. Rev., to be published.

[3] A.T. Skjeltorp, C.A. Catanese, H.E. Meissner and W.P. Wolf, Phys. Rev., to be published.

[4] C.A. Catanese, A.T. Skjeltorp, II.E. Meissner and W.P. Wolf, Phys. Rev. to be published.

[5] R.B. Clover and W.P. Wolf, Solid State Commun. 6 (1968) 331.

[6] K.H. Gobrecht, J.J. Veyssie and L. Weil, Ann. Acad. Sci. Fenn., Ser. A VI 210 (1966) 63.

[7] K.N. Lee, R. Bachmann, T.H. Geballe and J.P. Maita, Phys. Rev. B2 (1970) 4580.

[8] F.J. Morin and J.P. Maita, Phys. Rev. 129 (1963) 1115.

[9] M. Murabayashi, Y. Takahashi and T. Mukaibo, J. Nucl. Sci. Technol. 7 (1970) 312.

[10] P.F. Sullivan and G. Seidel, Phys. Rev., 173 (1968) 679.

[11] T.F. Smith and N.E. Phillips, in: Les Proprietes Physiques des Solides Sous Pression (Centre National de la Recherche Scientifique, Paris, 1970) p. 191.

[12] D.W. Osborne, Ann. Acad. Sci. Fenn., Ser. A VI 210 (1966) 53.

[13] E.F. Westrum, Jr., in: Progress in the Science and Technology of the Rare Earths, Vol. 3, ed. L. Eyring (Pergamon Press, Oxford, 1968) p. 459.

[14] C.E. Holley, Jr., E.J. Huber, Jr. and F.B. Baker, in: Progress in the Science and Technology of the Rare Earths, Vol. 3, ed. L. Eyring (Pergamon Press, Oxford, 1968), p. 343.

[15] J.R. Henderson, M. Muramoto and J.B. Gruber, J. Chem. Phys. 46 (1967) 2515.

[16] J.R. Henderson, M. Muramoto and J.B. Gruber, J. Chem. Phys. 47 (1967) 5097.

[17] P. Kisliuk, W.F. Krupke and J.B. Gruber, J. Chem. Phys. 40 (1964) 3606.

[18] J.B. Gruber, W.F. Krupke and J.M. Poindexter, J. Chem. Phys. 41 (1964) 3363.

[19] B.H. Justice, E.F. Westrum, Jr., E. Chang and R. Radebaugh, J. Phys. Chem. 73 (1969) 333; cf. B.H. Justice and E.F. Westrum, Jr., J. Phys. Chem. 73 (1969) 1959 and earlier references.

[20] T.S. Yashvili, D.Sh. Tsagareishvili and G.G. Gvelesiani, Teplofiz. Vys. Temp. 6 (1968) 817.
[21] T.S. Yashvili, D.Sh. Tsagareishvili and G.G. Gvelesiani, Soobshch. Akad. Nauk Gruz. SSR 46 (1967) 409.

[22] D.Sh. Tsagareishvili, T.S. Yashvili and G.G. Gvelesiani, Soobshch. Akad. Nauk Gruz. SSR 49 (1968) 175.

[23] D.Sh. Tsagareishvili, G.G. Gvelesiani and T.S. Yashvili, Zh. Fiz. Khim. 43 (1969) 882.

[24] G.G. Gvelesiani, D.Sh. Tsagareishvili and T.S. Yashvili, Izv. Akad. Nauk SSSR, Neorg. Mater. 4 (1968) 553.

[25] D.Sh. Tsagareishvili and G.G. Gvelesiani, Teplofiz. Vys. Temp., 9 (1971) 643.

[26] G.C. Fitzgibbon, D. Pavone and C.E. Holley, Jr., Proc. Eighth Rare Earth Research Conference (Reno, Nevada) (1970) p. 224.

[27] V.V. Tikhonov and I.A. Smirnov, Fiz. Tyerd. Tela. 13 (1971) 2749; V.V. Tikhonov, A.V. Golubkov and I.A. V.V. Tikhonov, A.V. Golubkov and I.A. Smirnov, Fiz. Tverd. Tela., 8 (1966) 3578.

[28] I.E. Paukov, V.V. Nogteva and E.I. Yarembash, Zh. Fiz. Khim. 40 (1966) 3094.

[29] I.E. Paukov, V.V. Nogteva and E.I. Yarembash, Zh. Fiz. Khim. 42 (1968) 998.

[30] I.E. Paukov, V.V. Nogteva and E.I. Yarembash, Zh. Fiz. Khim. 43 (1969) 2351.

[31] V.V. Nogteva, I.E. Paukov and E.I. Yarembash, Zh. Fiz. Khim. 43 (1969) 2344.

[32] V.V. Tikhonov, M.V. Romanova, I.A. Smirnov and V.M. Sergeeva, Fiz. Tverd. Tela. 7 (1972) 1697.

[33] O.D. McMasters, K.A. Gschneidner, Jr., F. Kaldis, and G. Sampietro, Chapter from Proc. Tenth Rare Earth Research Conf. (Carefree, Arizona, 1973) p. 970.

[34] E.F. Westrum, Jr., et al., unpublished data.

[35] J.H. Colwell, private communication.

[36] M.A. Bredig et al., Oak Ridge National Laboratory, reports and private communications.

[37] F.H. Spedding, D.C. Rulf and B.C. Gerstein, J. Chem. Phys. 56 (1972) 1498.

[38] J.W. Cobble, Annual Review of Physical Chemistry 17 (1966) 15.

[39] F. Varsanyi, K. Andres and M. Marezio, J. Chem. Phys. 50 (1969) 5027.

[40] J.H. Colwell, B.W. Mangum and D.B. Utton, Phys. Rev. 181 (1969) 842.

[41] J.M. Haschke, J. Chem. Thermodyn. 5 (1973) 283.

[42] J.L. Holm and F. Grønvold, Acta. Chem. Scand. 26 (1972) 1733.

[43] F.H. Spedding and D.C. Henderson, J. Chem. Phys. 54 (1971) 2476.

[44] G.P. Dudchik, O.G. Polyachenok and G.I. Novikov, Zh. Fiz. Khim. 45 (1971) 728.

[45] G.P. Dudchik, O.G. Polyachenok and G.I. Novikov, Zh. Fiz. Khim. 45 (1971) 728.

[46] A.K. Chaudhuri, Diss. Abstr. B 28 (1967) 1875.

[47] O.G. Poly achenok, Zh. Neorg. Khim. 12 (1967) 851.

[48] E.F. Westrum, Jr., in: Les Elements Des Terres Rares (Editions du Centre National de la Recherche Scientifique, Paris, 1970) p. 443.

[49] E.F. Westrum, Jr., H.L. Clever, J.T.S. Andrews and G. 
Feick, in: Rare Earth Research III, ed. L. Eyring, (Gordon and Breach, New York, 1966) p. 597.

[50] E.F. Westrum, Jr. and W.G. Lyon, in: Thermodynamics of Nuclear Materials, 1967 (IAEA, Vienna, 1968) p. 239.

[51] J.P. Mercurio, J. Ftourneau and R. Naslain, CHDAAK268B (1969) p. 1766.

[52] T.H. Geballe, B.T. Matthias, K. Andres, J.P. Maita, A.S. Cooper and E. Corenzwit, Science 160 (1968) 1443.

[53] B.T. Matthias, Phys. Letters 27A (1968) 511.

[54] W.E. Wallace, C. Deenadas, A.W. Thompson and R.S. Craig, J. Phys. Chem. Solids 32 (1971) 805.

[55] J.J. Veyssie and F. Anselin, Colloq. In. Centre. Nat. Rech. Sci. 157 (1967) 349.

[56] W. Stutius, Phys. Kondens. Mater. 10 (1969) 152.

[57] E.F. Westrum, Jr., in: Lanthanide/Actinide Chemistry, ed. R.F. Gould (American Chemical Society, Washington, D.C. 1967) p. 25.

[58] G.H. Dieke, Spectra and Energy Levels of Rare Earth Ions in Crystals (Interscience Publishers, New York, 1968).

[59] E.F. Westrum, Jr. and W.G. Lyon, in: Thermodynamics of Nuclear Materials, 1967 (IAEA, Vienna, 1968) p. 239.

[60] N.E. Phillips, J.C. Ho and T.F. Smith, in: Proc. Tenth Int. Conf. on Low Temperature Physics, Moscow (1966) p. 437.

[61] H.E. Flotow and D.W. Osborne, Phys. Rev. 151 (1966) 564.

[62] J.A. Lee, P.W. Sutcliffe and K. Mendelssohn, Phys. Lett. A30 (1969) 106.

[63] T.A. Sandenaw, J. Phys. Chem. Solids 26 (1965) 1075.

[64] T.A. Sandenaw and R.B, Gibney, J. Chem. Thermodyn. 3 (1971) 85 .

[65] J.C. Taylor and P.F.T. Linford, Cryogenics 7 (1967) 305.

[66] J.A. Lee, K. Mendelssohn and P.W. Sutcliffe, Cryogenics 5 (1965) 227.

[67] K. Mendelssohn, Acta Phys. Pol. A 38 (1970) 459.

[68] J.J. Huntzicker and E.F. Westrum, Jr., J. Chem. Thermodyn. 3 (1971) 61.

[69] R.A. Hein, L.H. Sjodahl and R. Szwarc, J. Nucl. Mater. 25 (1968) 101.

[70] R.A. Hein, P.N. Flagella and J.B. Conway, J. Amer. Ceram. Soc. 51 (1968) 291.

[71] L. Leibowitz. L.W. Mishler and M.G. Chasanov, J. Nucl. Mater. 29 (1969) 356.

[72] C. Affortit, High Temp. High Pressures 1 (1969) 27.

[73] D.R. Fredrickson and M.G. Chasanov, J. Chem. Thermodyn. 2 (1970) 623.

[74] F.C. Grønvold et al., J. Chem. Thermodyn. 2 (1970) 630.

[75] J.F. Kerrisk and D.G. Clifton, Nucl. Technol. 16 (1972) 531.

[76] A.C. Macleod, J. Chem. Thermodyn. 4 (1972) 699.

[77] K. Goto, Solid State Commun. 6 (1968) 653.
[78] H.E. Flotow, D.W. Osborne and E.F. Westrum, Jr., J. Chem. Phys. 49 (1968) 2438.

[79] T.D. Chikalla, C.E. McNeilly, J.E. Bates and J.J. Rasmussen, Nucl. Sci. Abstr. 26 (1972) 7219.

[80] L. Eyring, in: High Temperature Oxides, ed. A.M. Alper, (Academic Press, New York, 1970) p. 41.

[81] M. Hoch, High Temp. High Pressures 4 (1972) 493.

[82] D.I. Marchidan and S. Matei, Rev. Roum. Chim. 17 (1972) 195; 15 (1970) 1491.

[83] D.I. Marchidan and M. Ciopec, Rev. Roum. Chim. 17 (1972) 1657.

[84] K. Maglic and R. Herak, personal communication.

[85] H.L. Girdhar and E.F. Westrum, Jr., J. Chem. Eng. Data 13 (1968) 531.

[86] E.H.P. Cordfunke and E.F. Westrum, Jr., unpublished results.

[87] M. Tetenbaum and P.D. Hunt, J. Chem. Phys. 49 (1968) 4739.

[88] V.J. Wheeler, J. Nucl. Mater. 39 (1971) 315.

[89] T.L. Markin, V.J. Wheeler and J.R. Bones, J. Inorg. Nucl. Chem. 30 (1968) 807.

[90] F. Grønvold, N.J. Kveseth, A. Sveen and J. Tichy, J. Chem. Thermodyn. 2 (1970) 665.

[91] D.I. Marchidan and S. Matei, Rev. Roum. Chim. 17 (1972) 1487.

[92] P. Gerdanian and M. Dode, C. R. Acad. Sci. Paris 262 (1966) 796.

[93] S. Abramowitz and N. Acquista, J. Phys. Chem. 76 (1972) 648 .

[94] O.L. Kruger and H. Savage, J. Chem. Phys. 49 (1968) 4540 .

[95] A.E. Ogard, Nucl. Met., Met. Soc. AIME 17 (1970) 78.

[96] L. Manes, Nucl. Met., Met. Soc. AIME 17 (1970) 254.

[97] A.E. Ogard and J.A. Leary, in: Thermodynamics of Nuclear Materials, 1967 (IAEA, Vienna, 1968) p. 651.

[98] C. Affortit and J.P. Marcon, Rev. Int. Hautes Temp. Refract. 7 (1970) 236.

[99] C. Affortit, Nucl. Sci. Abstr. 26 (1972) 31487.

[100] H.E. Flotow, D.W. Osborne and R.R. Walters, J. Chem. Phys. 55 (1971) 880.

[101] E.F. Westrum, Jr., R.R. Walters, H.E. Flotow and D.W. Osborne, J. Chem. Phys. 48 (1968) 155.

[102] Y. Takahashi and E.F. Westrum, Jr., J. Phys. Chem. 69 (1965) 3618.

[103] A.C. Macleod and S.W.J. Hopkins, Proc. Brit. Ceramic Soc. 8 (1967) 15.

[104] F. Grønvold and E.F. Westrum, Jr., J. Inorg. Nucl. Chem. 30 (1968) 2127.

[105] E.F. Westrum and F. Grønvold, J. Inorg. Nucl. Chem. 32 (1970) 2169.

[106] J.F. Counsell, J.F. Martin, R.M. Dell and A.R. Junkison, Nucl. Sci. Abstr. 22 (1968) 31470.

[107] C. Affortit, J. Nucl. Mater. 34 (1970) 105.

[108] J.F. Martin, Proc. Brit. Ceramic Soc. 8 (1967) 1.

[109] E.F. Westrum, Jr., Y. Takahashi and N.D. Stout, J. Phys. Chem. 69 (1965) 1520. 
[110] L.C. Harrington, Report CNLM-4318 (1971) [cf. NSA, 11, 26, Abstract 25953 (1972)].

[111] F.L. Oetting, J.D. Navtratil and E.K. Storms, J. Nucl. Mater., 45 (1972/73) 271.

[112] T.A. Sandenaw, R.B. Gibney and C.E. Holley, J. Chem. Thermodyn. 5 (1973) 41.

[113] T.A. Sandenaw and R.B. Gibney, Nucl. Met., Met. Soc. AIME 17 (1970) 104.

[114] J. Danan, J. Nucl. Mater. 45 (1972/73) 339.

[115] E.F. Westrum, Jr. and C.M. Barber, J. Chem. Phys. 45 (1966) 635.

[116] J. Danan, C.H. De Novion and H. Dallaporta, Solid State Commun. 10 (1972) 775.

[117] J.O. Scarbrough, H.L. Davis, W. Fulkerson and J.O. Betterton, Jr., Phys. Rev. 176 (1968) 666.

[118] E.H.P. Cordfunke and M.M. Aly, J. Nucl. Mater. 42 (1972) 233

[119] M. Murabayashi, Y. Takahashi and T. Mukaibo, J. Nucl. Mater. 40 (1971) 353.

[120] F.L. Oetting and J.M. Leitnaker, J. Chem. Thermodyn. 4 (1972) 199.
[121] K.E. Spear and J.M. Leitnaker, J. Amer. Ceram. Soc. 51 (1968) 706.

[122] K.E. Spear and J.M. Leitnaker, Nucl. Sci. Abstr. 22 (1968) 17176

[123] H. Tagawa, J. Nucl. Mater. 41 (1971) 313.

[124] H.E. Flotow, D.W. Osborne, P.A. O'Hard, J.L. Settle, F.C. Mrazek and W.N. Hubbard, J. Chem. Phys. 51 (1969) 583.

[125] D.R. Fredrickson, R.D. Barnes, M.G. Chasanov, R. Nuttall, R. Kleb and W.N. Hubbard, High Temp. Sci. 1 (1969) 373.

[126] D.R. Fredrickson, R.D. Barnes, M.G. Chasanov, R. Nuttall, R. Kleb and W.N. Hubbard, High Temp. Sci. 2 (1970) 299.

[127] A.S. Dworkin, J. Inorg. Nucl. Chem. 34 (1972) 135.

[128] F.L. Oetting, Chem. Rev. 67 (1967) 261.

[129] M.H. Rand, D.T. Livey, P. Feschotte, H. Nowotny, K. Seifert and R. Ferro, At. Energy Rev. 4, Special Issue No. 1 (1966).

[130] J.J. McBride and E.F. Wcstrum, Jr., unpublished data. 